\title{
O FILME NO CAMPO EDITORIAL: THE WORDS, 2012, DE B. KLUGMAN E L. STERNTHAL
}

\author{
The film in the editorial field: The words, 2012, de B. Klugman and L. Sternthal \\ La película en el campo editorial: The words, 2012, por B. Klugman y L. \\ Sternthal
}

Marília de Araujo Barcellos

Departamento de Ciências da Comunicação

Universidade Federal de Santa Maria

e-mail:mariliabarcellos@gmail.com

\section{Resumo}

A proposta deste artigo é perceber a presença de elementos pertinentes ao campo editorial no filme intitulado As palavras, The words, no original, dirigido por Brian Klugman e Lee Sternthal, com estreia em 2012. A narrativa discorre sobre a história de três escritores e o plágio de um texto que leva à consagração o autor equivocado. $\mathrm{O}$ referencial teórico conta com postulados de Pierre Bourdieu, John B. Thompson e Roger Chartier, cujo resultado é uma análise que pontua os agentes formadores do campo, numa cadeia de valor que vai do autor ao leitor, passando por etapas da produção editorial, na qual se enquadram a divulgação e o marketing. O propósito, ao fim e ao cabo, não consiste em saber se houve plágio, ou não, mas, sim, no quanto um original datilografado, engavetado, ou sem se fazer circular e alcançar seu público, precisa ser publicado para pertencer ao campo editorial.

Palavras-chave: Comunicação. Campo editorial. Cadeia produtiva do livro.

\begin{abstract}
The proposal of this article is to perceive the presence of elements pertinent to the editorial field in the american film entitled The words, directed by Brian Klugman and Lee Sternthal, premiered in 2012. The narrative tells the story of three writers and the plagiarism of a text that leads to the consecration of the wrong author. The theoretical reference has postulates by Pierre Bourdieu, John B. Thompson and Roger Chartier, whose result is an analysis that punctuates the agents that form the field, in a value chain that goes from the author to the reader, passing through stages of editorial production, in which are the dissemination and marketing. The purpose, after all, is not to know if there has been plagiarism, or not, but how much an original typed, bottled, or without circulating and reaching its public, needs to be published to belong to the editorial field.
\end{abstract}

Key words: Communication. Editorial field. Production chain of the book.

\section{Resumen}

La propuesta de este artículo es percibir la presencia de elementos pertinentes al campo editorial en la película titulada The words, en el original, dirigida por Brian Klugman y Lee Sternthal, estrenada en 2012. La narración cuenta la historia de tres escritores y el plagio de 
un texto que lleva a la consagración del autor equivocado. El marco teórico incluye postulados de Pierre Bourdieu, John B. Thompson y Roger Chartier, cuyo resultado es un análisis que puntualiza a los agentes que forman el campo, en una cadena de valor que va desde el autor hasta el lector, pasando por etapas de producción editorial, en las que encajan la difusión y la comercialización. El propósito, al fin y al cabo, no es saber si ha habido plagio o no, sino más bien cuánto tendría que publicarse un original mecanografiado, embotellado o sin circular y llegar a su público, para pertenecer al campo editorial.

Palabras clave: Comunicación. Campo editorial. Cadena de producción del libro.

\section{INTRODUÇÃO}

Não há dúvidas de que o filme As palavras investe no acompanhamento do processo criativo, ao discorrer sobre história de escritores e seus dramas, tanto pessoais, quanto de ordem profissional. Eis, pois, o porquê de As palavras chamar atenção, principalmente, para a questão do entrelaçamento de histórias paralelas, ao mesmo tempo em que deixa entrever uma narrativa no decorrer de outra, fragmentada entre três supostos autores. A verdade é que se tem um filme dentro de outro filme. Um discurso dentro de outro discurso, contando a história de personagens-escritores, particularidades de suas vidas e de suas escrituras.

A proposta deste estudo é capturar a presença de elementos pertinentes ao campo editorial, mais especificamente aos da cadeia produtiva do livro, encerrados nessa película intitulada As palavras. E, a partir das informações apreendidas, verificar como são encaminhadas as estratégias de aproximação da lógica do campo editorial, conforme ensina o sociólogo Pierre Bourdieu. Entende-se aqui como cadeia produtiva os agentes formadores do campo - do autor ao leitor/consumidor -, passando pelas etapas da produção editorial, em que se enquadram a divulgação e o marketing. O exercício de bricolagem entre as histórias apresentadas no filme encontram-se bem identificadas pelo núcleo de cada uma das personagens que encaminham o enredo, e de cujo cerne emergem três histórias de escritores.

Talvez se possa pensar em um jogo de metanarrativas, para discorrer a respeito dos bastidores da autoria: em um momento, a angústia da página em branco; em outro, a conquista do status de celebridade; e, em paralelo, a existência do anonimato. Cada personagem/autor, uma história. Cada história, uma situação, um tempo, um espaço, uma configuração de estrutura familiar. $\mathrm{O}$ roteiro do filme entretém-se com a tênue fronteira entre a ficção e a realidade. E, no final, caberá ao espectador, somente a ele, definir tal perspectiva, conforme se constatará a seguir.

\section{HISTÓRIA DO FILME}


Ao se considerar o texto como palavras alinhadas que contam histórias, o propósito deste estudo passa a ser acompanhar essas palavras encarreiradas na obra em tela, como fio condutor dessa narrativa que entrelaça a tríade autorias-histórias-autores e amores. Um jogo em que o tabuleiro representa o mundo editorial, e cujas peças são constituídas de livros e escritores, em permanente embate com as personagens e suas relações no seio da vida familiar, além dos autores entre si, e em meio à posição profissional que ocupam e à função que desempenham e, também, à específica propriedade intelectual junto ao mercado.

Esse filme, de nacionalidade norte-americana, estreou em 2012, e fora escrito e dirigido pelos roteiristas Brian Klugman e Lee Sternthal. Trata-se de uma narrativa em prosa, a relatar a vida de escritores que, para facilitar o entendimento dos leitores, assim os caracteriza: escritor consagrado, nomeado como Clayton Hammond, também chamado de Clay (encenado por Danniel Quait); Rory Jansen, no papel do jovem escritor (interpretado pelo ator Bradley Cooper), na verdade uma criação literária do autor consagrado; e o escritor que surge do passado, autor desconhecido, chamado de "o velho homem" (interpretado por Jeremy Irons), o verdadeiro autor do texto premiado, indiretamente endereçado a Rory.

A obra inicia-se com a tomada de posição da personagem Clayton Hammond, no papel de um escritor em seu ambiente de trabalho, em meio aos objetos simbólicos da profissão. Sobre a mesa organizada, vê-se: o livro The words, uma caneta sobre esse livro, uma carteira de dinheiro e, em cima dela, um molho de chaves; ao lado, uma agenda. Uma personagem não identificada - uma vez que seu rosto não é exibido - sexo masculino, vestindo paletó e gravata. Coloca a agenda no bolso do casaco, a carteira e as chaves no bolso da calça, e a caneta na parte interna do paletó. Uma aliança na mão esquerda indica o compromisso matrimonial. Observa-se nele, ainda, pequenos detalhes: o terno elegante induz uma ocasião especial; a aliança de casado expõe a personagem que com ele contracena e que terá relevância na história; a caneta, instrumento de trabalho, para além das mídias técnicas, como o computador e o celular; por fim, o livro, de design caprichado, produzido em capa dura, formato luxo, materialidades que compõem a história.

Em ambiente de arquitetura pós-moderna, vidros amplos, prédios tipo arranha-céus emoldurados por colunas e vidraças voltadas para a rua, conforme se constata no final do filme, já que é nesse mesmo ambiente que As palavras se encerra. Na indumentária, entrevêse os punhos brancos da camisa sob o casaco preto, abotoado de cima a baixo, seguido pela adequação da gravata, a sinalizar que a ocasião requer traje social, exige luxo. O livro está firmemente protegido e seguro em sua mão esquerda, a mesma que ostenta o símbolo do 
compromisso, ou seja, a aliança dourada. Assim, de posse dos objetos, o escritor encaminhase para a porta, a fim de atender e honrar um compromisso: receber o prêmio. Ocasião em que obterá o reconhecimento da sociedade, de seus pares, do público, enfim. Partindo da esfera privada, para adentrar o espaço público, direciona-se para o evento social, onde, ao que parece, fará a leitura da obra em voz alta para uma atenta plateia.

A cena é movente. $\mathrm{O}$ foco parte do detalhe e segue em direção ao panorâmico, quando se percebe todo o ambiente privado, o espaço de trabalho do escritor. Em seguida, passa para o espaço público. A cena subsequente acontece no tempo presente, em que a personagem Clay, que passará a se chamar aqui de 'escritor consagrado', lê em alta voz excerto de sua obra The world, para o auditório lotado do evento.

Inicia-se a narração: "Parte um: o velho está na chuva. Viu como Rory e Dora Jansen [interpretada por Zöe Saldana] foram para a limusine." (1'51'). Em menos de dois minutos de filme, são apresentadas as três personagens, cujas vidas se entrelaçam ao longo da narrativa, em meio a uma imbricada relação de autoria e escrita. O livro dentro do filme antecipa o conflito: o autor do original, homem em idade avançada, o velho homem, que toma remédios em um quarto de hotel, com o livro em mãos, porém sem aliança na mão esquerda. E o jovem escritor, em uma limusine, auge do reconhecimento, com a esposa, em importante momento da carreira. Todos de gravata, denotando a importância do acontecimento social.

Clay lê para a audiência presente no auditório - no mínimo, umas 250 pessoas, a julgar pela imagem que possibilita contar 15 poltronas por 10, na fileira do meio, e em torno de três por 10 em cada lateral. O que está em causa é a história de um escritor jovem, sem inspiração, que está sendo agraciado com um prêmio, embora se sinta acossado por um fantasma, a acusá-lo de ter-lhe subtraído o texto que outrora escrevera, quer dizer, de ter-se assenhoreado de sua obra. E a narrativa do livro dentro do livro prossegue. Clay apresenta o autor (talvez se possa considerar como seu alter ego). Em voz alta prossegue: [Rory] "lutava para fazer sua arte. Viver como todos os grandes escritores que idolatrava. (...) um jovem escritor lutando para sua voz ser ouvida)" (6'47', - 7'15',). Revela-se o casamento de Rory e Dora. A lua de mel em Paris é um marco do roteiro, pois, durante a viagem, o fato de encontrarem "a pasta", ao que parece em uma loja de antiguidades, tem, como consequência, o início de uma nova fase para o escritor.

O conflito surge quando se manifestam questões internas de Rory, divergindo do esperado. A personagem assume uma recompensa que não é sua, ou seja: é-lhe oferecido um prêmio e ele aceita, a despeito de saber não merecida essa distinção que lhe concedem, 
porquanto é-lhe indevida. Daí se sentir um tanto constrangido e até mesmo pressionado em seu interior. Contudo, o desconforto moral não foi suficiente para quebrar-lhe a presunçosa expectativa de assumir o papel de vencedor. E isso se amplia ainda mais, quando o escritor e verdadeiro autor da obra apresenta-se e conta a sua história. Revela-se, nesse momento, ao que tudo indica, uma metahistória de autoria, uma vez que o escritor daquelas linhas, o verdadeiro autor daquelas palavras, consignara em páginas extraviadas ao longo do tempo uma passagem dolorosa de sua biografia. Eis que desponta, então, um “spoiler” - quem escrevera a obra fora um desconhecido, e quem acabou recebendo os louros do triunfo fora um outro escritor contemporâneo, denominado Rory, anos depois de o original - escondido no forro de uma pasta de couro sanfonada - ter sido deixado pela esposa da personagem em um vagão de trem de Paris, personagem essa interpretada no filme pelo ator Jeremy Irons,

O desespero sentido pelo autor por culpa do material perdido é entendido como um desapego, um deixar fluir, em relação a uma situação de vida que não mais lhe cabia sofrer por ela. Tal como correm as águas de um rio, o tempo fez com que o conteúdo não mais tivesse o mesmo sabor, a mesma textura, a mesma temperatura, ao perpassar pelo fluxo da vida. O velho homem reconsidera e se abstém da relevância de ocupar aquele lugar outrora almejado de escritor, para, em vez disso, resgatar aquele mesmo sentimento que, remotamente, levou-o a escrever para contar sua história. Nesse sentido, a obra As palavras traz algumas reflexões bastante relevantes: Por que se escreve? Qual o sentido da escrita? Qual o significado do plágio? Qual o valor da propriedade intelectual? Como surge um escritor?

A cada peça do tabuleiro, dá-se o nome de agente; ao mundo no qual acontecem as relações durante a história, caracteriza-se como 'campo'. Por se tratar de um universo de escritores, de livros e de leitores, intitula-se como 'campo editorial'. Os elos que se formam entre esses elementos, de maneira orgânica e sistêmica - considerados relações entre os agentes envolvidos em rede que se estabelecem em cadeia - qualificam-se como 'cadeia produtiva do livro'. Portanto, o artigo discorre sobre as relações dos agentes formadores da cadeia produtiva do livro no campo editorial. E, como subsídio, a análise do filme As palavras.

\section{CAMPO EDITORIAL E CADEIA PRODUTIVA}


A cadeia produtiva do livro reúne atores com múltiplas competências e atuações no campo aqui considerado, a partir de Pierre Bourdieu, em uma releitura de John B. Thompson, quando ele afirma que o

(...) espaço estruturado de posições sociais, que pode ser ocupado por agentes e organizações e no qual a posição de qualquer agente ou organização depende do tipo e da quantidade de recursos ou "capital" que eles têm à sua disposição (...) os mercados uma parte importante de alguns campos; porém, os campos são sempre mais do que mercados. Eles se constituem de agentes e organizações de diferentes tipos e de diferentes níveis de poder e recursos, de uma variedade de práticas e de formas específicas de concorrência, colaboração e recompensa. (THOMPSON, 2013, p. 9-10).

No caso em foco, está-se referindo ao campo editorial, com a presença dos agentes e a relação entre eles, conforme a lógica de atuação. Portanto, há de se tratar aqui de analisar os elementos do campo editorial constantes no filme As palavras, verificando, conforme seus movimentos de atuação, se eles ocupam instâncias distintas no mundo da edição.

Considera-se que, em As palavras, tem-se um conjunto de criadores, ou de fazedores, ou de..., não importa, haja vista constar nele autores, agentes literários, obras, editores, jornalistas e leitores. Por sua vez, a organização está representada pela Academia Americana de Artes e Letras, com a premiação da obra. Cada um desses elementos desdobra-se em tensões a serem abordadas, e que refletem a complexidade do campo. Em relação ao escritor, evidencia-se a angústia da influência, a luta contra a página em branco, as dificuldades econômicas diante da pouca valorização profissional, o trabalho da escrita no ambiente privado e suas consequências no âmbito familiar. No que tange à obra, a originalidade e a questão do plágio; em relação à editora, a seleção dos originais, o risco da publicação, o investimento em autores jovens, as etapas de produção da seleção do original, a divulgação e as vendas. E mais: os leitores e o público consumidor com suas exigências, o engajamento com a recepção da narrativa, seja ela respeitante ao real, ou ao imaginário.

Respeitante aos recursos capitais das editoras, mais uma vez há de se retomar o pensamento do sociólogo Pierre Bourdieu (1982), ao destacar o equilíbrio entre o capital de bens simbólicos (status; prestígio acumulado), e o capital econômico (o financeiro, o estoque, a reserva de capital), para que haja harmonia na empresa (BOURDIEU, 1982).

Além desses dois eixos principais, Thompson acrescenta outros três recursos, a saber: capital humano (equipe qualificada de trabalho); capital social (redes de contatos e relações); capital intelectual (propriedade intelectual, autores, contratos). Os recursos à disposição da 
editora garantem o poder de agir e de se movimentar no campo, conforme o capital que estiver disponível.

Os elementos formadores do campo e pertencentes à cadeia produtiva são definidos como cadeia de suprimentos e cadeia de valor. Esta última, vale frisar, será utilizada para ancorar este estudo. O conjunto de fatores que determinam as condições em que os agentes de organizações participam, atuam e interagem no campo é chamado de lógica (THOMPSON, 2013), por se referir à lógica estabelecida pelas trocas no campo, postulada pelo sociólogo Pierre Bourdieu, e que se caracteriza “(...) pelas regras estabelecidas, visando a determinar as funções dos participantes desse espaço". (In: GARCIA; BARCELLOS, 2015).

Cabe ressaltar, ademais, que Thompson expande o conceito e introduz a questão da pluralidade de campos, induzindo o leitor a perceber a existência de 'mundos' que se relacionam entre si, tais como o da literatura infantil, os dos livros de arte, dentre outros exemplos que se designam por especificidades para além da divisão de livros eruditos, ou de livros de ficção. O pesquisador Jaimeson Machado Garcia (2014, p. 11), em um trabalho a esse propósito, resume bem o conceito de campo e de suas pluralidades, conforme observa Thompson (2013):

Dessa forma, o autor argumenta que a primeira razão para considerar o mundo editorial como um campo é a de que ele não é único, e, sim, composto por vários outros campos devido à pluralidade de publicações. Essa pluralidade de publicações refere-se à bibliodiversidade, conceito utilizado para denominar os mais variados tipos de conteúdos que podem ser publicados. (GARCIA, 2014, p. 11).

Entende-se aqui como livros, aqueles conteúdos produzidos e editados, que passaram pelas etapas do processo de edição e que participaram da cadeia produtiva da indústria editorial. Nesse sentido, a Figura 1 desvela essa cadeia e seus elementos, cuja participação estabelece a cadeia de valor da publicação.

Figura 1- Cadeia de valor 


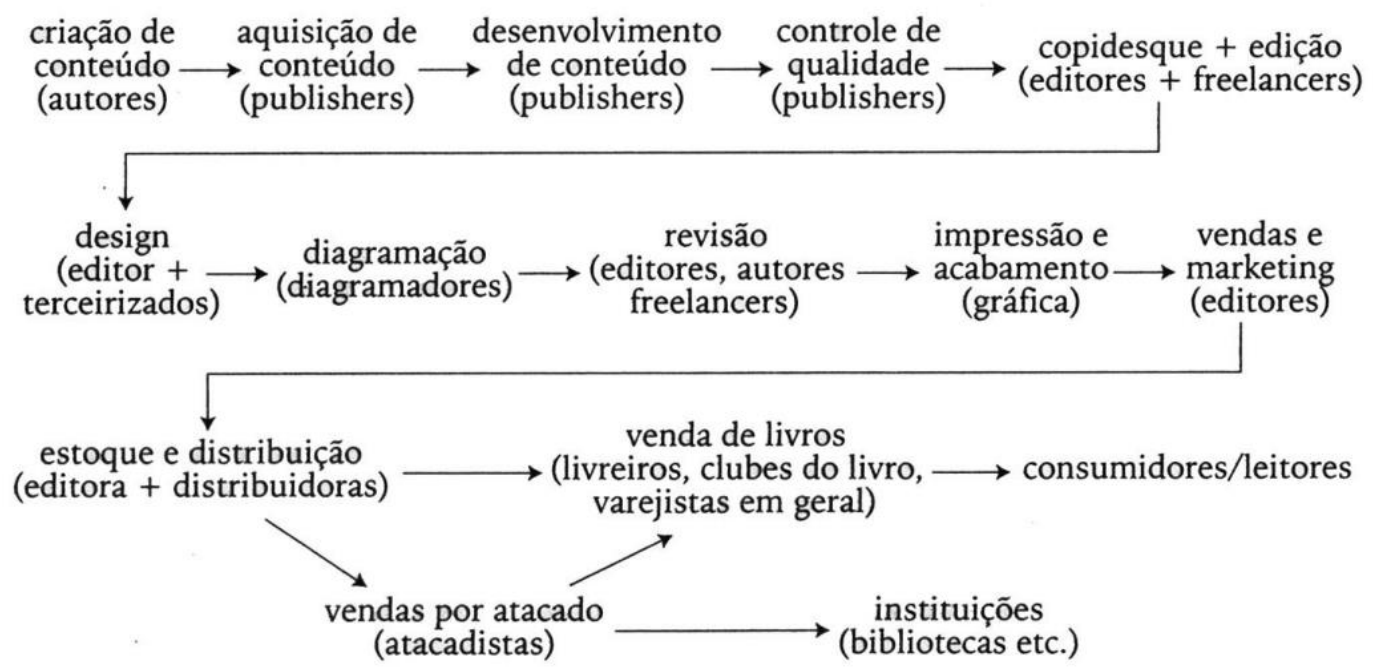

Fonte: John B. Thompson, 2013, p. 22.

Como é possível observar, o sistema de produção na indústria editorial contém agentes que se repetem, independente do modelo de negócios a ser selecionado. Em outras palavras: para que haja um conteúdo, deve haver um autor; para que haja produção, deve haver agente para publicação (mesmo que se trate de uma autopublicação, conforme as práticas atuais); e deve haver, também, um processo com etapas de produção que envolvam texto e imagem, preparação, revisão de originais, projeto gráfico, diagramação, e, posteriormente, impressão. Portanto, o campo editorial representa uma cadeia com agentes em funções distintas, e, por vezes, sobrepostas. No entanto, o que se vai perseguir aqui é o quanto esses elementos surgem no filme. O quanto se pode analisar a autoria no processo de criação literária, na divulgação, no marketing e no que diz respeito ao público-consumidor, no decorrer da narrativa fílmica de As palavras.

\section{CRIAÇÃO DE CONTEÚDO E QUESTÕES DE AUTORIA}

No quadro da cadeia de valor no campo editorial, anteriormente apresentado, pode-se perceber que a criação do conteúdo, função da escrita, representa a primeira etapa do sistema. Quando se estabelece a relação da cadeia produtiva do livro, no filme As palavras, está-se referindo, por exemplo, à posição dos escritores no campo. Um exemplo disso é Rory Jansen, o jovem escritor como personagem, que se torna profissional de uma editora. Posteriormente, porém, segundo o filme, recebe o prêmio da American Fellowship of Arts and Letters ${ }^{1}$

\footnotetext{
1 “Academia Americana de Artes e Letras é uma sociedade de honra dos 250 principais arquitetos, artistas, compositores e escritores do país. A cada ano, elege novos membros, à medida que ocorrem vagas; administra mais de 70 prêmios e exibe arte e manuscritos; financia obras de novas obras de teatro musical e compra obras de arte para doação a museus nos Estados Unidos" (ARTSANDLETTERS, s|d)
} 
(Associação Americana de Artes e Letras), pela obra intitulada Lágrimas da janela (tal como fora premiado o escritor Clay). As dificuldades financeiras que o filme descortina, com Rory buscando apoio na figura paterna, para obter recursos, leva a refletir a respeito do papel do autor na sociedade. O diálogo que se estabelece entre pai e filho, a propósito da vida profissional do escritor e a dependência econômica estabelecida, é tema recorrente na literatura. Muitos outros autores têm surgido assumindo esse papel em narrativas, em romances, ao longo da história.

A temática é direcionada para o contexto de autores em início de carreira, autores esses que necessitam financeiramente de “paitrocínio'. A certeza de que precisa de tempo para produzir o bestseller que há de garantir a subsistência constitui condição sine qua non para se sentir parte integrante da sociedade como profissional. Uma pergunta apenas: seria esse filme condizente com a atualidade, cenário da autopublicação e do financiamento coletivo? A questão fica em aberto, porque logo se verá que essa não constitui a trama única da história.

No filme, sob uma lógica que se pode denominar de usual, os dois escritores percorrem o caminho da publicação tradicional, feito pelas editoras. E, dos três, o chamado de 'desconhecido' tem sua obra publicada por meio de plágio de um manuscrito. A seguir, um pouco dessa história.

\subsection{O ofício de escritor e a criação literária}

A elipse de tempo que joga autor-personagem-autoria no enredo entrelaça histórias de vida e confunde o leitor, esse espectador que fica traçando para saber de quem se trata, se do autor de As palavras, ou se do narrador da história da autoria. Qual história está verdadeiramente sendo contada no filme? A narrativa evidencia a tensão familiar sobre a profissionalização do escritor, tema esse há muito pontuado na literatura e, certamente, muito recorrente em um sem número de escritos ao longo do tempo.

Ao trazer o drama financeiro da personagem aos espectadores, o do jovem escritor que vai 'passar o chapéu' para o pai colaborar, o filme aborda o quanto o capital financeiro está ligado a qualquer profissão, em especial àquelas atividades que não se enquadram nas chamadas "tradicionais". Rory, em seu diálogo com o pai: “- eu tive emprego desde os meus 15 anos. Era ajudante de garçom,...” 9'47”, para justificar sua atual condição: “- decidimos, nos últimos 2 anos, me dedicar a ser escritor”... Ao que o pai lhe responde: “- Então, talvez agora isso deva ser um passatempo, em vez de uma profissão (...)" 9'59', e prossegue 
insistindo para que tenha um emprego. E é a partir dessa situação que ele busca assumir, em uma instituição editorial, ou estabelecimento de publicação, "uma posição", contudo, não em qualquer delas, mas "em uma das maiores editoras". Todavia, sabe-se que uma posição no campo editorial não é exatamente a desejada por um autor, mas uma outra assumida na cadeia produtiva, "na esperança de fazer algumas conexões", ou seja, estabelecer o que Thompson denomina de 'capital social', quer dizer, instaurar relações de contato. Porém, mesmo nos bastidores da editora, os contatos com os colegas eram vagos, nada animadores. E Clay prossegue a leitura do drama.

$\mathrm{O}$ apoio de recurso financeiro familiar enquadra-se naquilo que Bourdieu destaca sobre a origem social e as condições para se ocupar uma posição frente à sociedade. Diz ele que

(...) é preciso perguntar não como tal escritor chegou a ser o que foi (...), mas como, sendo dadas a sua origem social e as propriedades socialmente constituídas que ele lhe devia, pôde ocupar ou, em certos casos, produzir as posições já feitas ou por fazer, oferecidas por um estado determinado do campo literário...” (BOURDIEU, 1996, p. 244).

Embora, inicialmente, Rory tenha se beneficiado da condição social familiar, foi por indicação/pressão paterna que ele saiu à busca de subsistência, empregando-se numa editora. Mesmo como agente de campo na empresa, esse cargo, ao que tudo indica, parece ocupar uma instância de poder inferior, já que aparece empurrando um carrinho cheio de livros pelos corredores da editora, a denunciar uma não participação na escala de tomadores de decisão. A análise da posição no campo do poder seria, conforme sugere Bourdieu, "o espaço das relações de força entre agentes ou instituições que têm em comum possuir o capital necessário para ocupar posições dominantes nos diferentes campos" (BOURDIEU, 1982, p. 243). Com o desenvolvimento do filme, essa posição permite-lhe conhecer os agentes literários que ali atuam ao encaminhar o original, e isso se faz de tal maneira, que lhe é possível perceber o agente negociar o contrato de Lágrimas da janela. E será esse mesmo agente que lhe há de socorrer na ocasião da revelação de plágio, sugerindo o pagamento para o verdadeiro autor do livro. Por conseguinte, na história, o fato de uma obra de Rory Jansen ter sido publicada pela editora, altera sua posição no campo, passando ele a ter influência na instância de poder.

Há de se encarar essa situação também em relação à carreira, à profissionalização do escritor nas atividades a serem realizadas no campo da edição, para além de escrever o livro. Acompanhando esse raciocínio, que se aproxime, pois, o próprio roteiro em que se abre a película, com um evento e a leitura em voz alta da obra As palavras. Nesse sentido, salienta- 
se que "a profissionalização do escritor aponta para a posição social em que o prestígio encontra-se acompanhado da labuta em elaborar o texto, e também da necessidade de estar disponível para participar de eventos, lançamentos, palestras e toda sorte de atividades que se situem na esfera da mediação" (BARCELLOS, 2006, p. 24).

Dizendo de outra maneira: a figura do autor como elemento mediador entre a obra e seu público torna-se elemento da cadeia produtiva no quesito vendas e marketing, por meio de sua divulgação no campo editorial. No filme, inclusive, percebe-se a imagem do autor, quando da chamada para a palestra - percorrendo um painel em toda a parede do hall da sala, onde o público se reúne no intervalo do evento - ao término da leitura da parte 1 da obra, como se verá mais adiante no desenvolvimento do assunto.

\subsection{O ofício de escritor como um sacrifício}

No rastro da vida de Ernest Hemingway, abre-se um portal para desvendar o filme, no sentido de ser ele um fio condutor da influência literária, já que surge mais de uma vez na tela. Uma das referências é histórica, com a inserção da placa comemorativa na cena em que Rory e Dora estão passeando pelas ruas de Paris, e encontram a residência onde morou Hemingway e sua esposa. A placa comemorativa ${ }^{2}$ afixada no Quartier Latin, revela onde morou o escritor enquanto redigia Paris é uma festa. Representa, na verdade, uma pincelada da primeira referência literária de um americano que assume a França como sua morada, para efetivar sua escrita, que irá ressurgir nas prateleiras do escritor desconhecido. Isso explica o poder da arte de Hemingway, como influência para o velho, e o porquê de a pasta estar colocada naquele lugar. Sutilezas do roteiro. Na placa que se encontra na Rue du Cardinal Lemoine, 74, $5^{\text {eme }}$, vê-se registrado 'Paris é uma festa', justamente por ser onde Hemingway desenvolveu sua obra, casa onde residiu de janeiro de 1922 a outubro de 1923. Foi nesse endereço que o escritor escreveu parte de sua criação e relatou, em Paris é uma festa, a pobreza em que vivia: "Sanitários antigos das velhas casas de apartamentos, um em cada andar, ao lado das escadas, com duas elevações de cimento estriado, em forma de sapato, para evitar que algum locatário escorregasse, davam para fossas que, à noite, eram esvaziadas (...)”

\footnotetext{
2 A placa com os dizeres: "De janeiro de 1922 a agosto de 1923, morou, no terceiro andar deste edifício, com Hadley, sua esposa, o escritor americano Ernest Hemingway, 1899-1961. O bairro, que ele amava acima de tudo, era o lugar real do nascimento de seu trabalho e o estilo despojado que o caracteriza. Esse americano em Paris mantinha relações familiares com seus vizinhos, em particular com o proprietário do bal-musette adjacente '... Essa foi a Paris da nossa juventude, quando éramos muito pobres e muito felizes. Ernest Hemingway (Paris é uma festa)'. Associação da Memória dos Lugares". Tradução livre (WIKILIVROS, s/d).
} 
(HEMINGWAY, 1969, p. 5). Em As palavras, o casal adentra o local repleto de objetos antigos e encontra a pasta.

Pontos em comum na criação da personagem Rory com a vida do escritor Ernest Hemingway? Pode ser. Mormente em relação à dificuldade financeira no início da carreira, e também ao ofício de escritor, além, é claro, de ter ele ocupado um papel singular na cadeia editorial, já que Hemingway atuou como revisor de Gertrude Stein.

Outras questões, como ter ou não talento, são tratadas no livro Escrever ficção, de Luís Antônio de Assis Brasil, quando o professor insinua que a palavra teria sido criada para atormentar as pessoas, por "gerar inumeráveis pseudoproblemas" (2019, p. 20). Ora, Rory sofre com a página em branco, é verdade, embora a digitação do manuscrito seja uma técnica bastante utilizada por escritores. O rumo que a história segue é que é a questão, passando do exercício para uma exposição, com comprometimento da imagem profissional.

\subsection{O agente literário, as editoras e a aquisição de conteúdo}

Pode-se dizer que da criação literária na cadeia de valor surge mais um elemento, que é o agente literário, responsável pela facilitação das negociações entre o autor e as editoras. No entanto, a declinar de tal assertiva - "ninguém apoiará um livro como este. De um desconhecido (...), não há mercado para isso," 16’23" - há de justificar o primeiro agente consultado por Rory. Desse modo, o autor, sucessivamente, recebe das editoras pareceres rejeitados. Alguns, assinados por assistentes editoriais: “(...) não estamos em condições de publicar seu manuscrito". E assim, uma a uma das cartas sugere texto-padrão das editoras, a negar o original. $O$ filme perpassa cinco cartas negativas datadas. Apesar da pouca possibilidade de leitura na tela, isto é, de se ler o texto com certa facilidade, no que diz respeito ao conforto visual, contudo, duas daquelas missivas são identificáveis - uma do mês de abril e outra do mês de outubro, ambas, porém, encontravam-se em mãos do jovem autor. Tratava-se de respostas agradecendo o envio dos textos e a oportunidade de ler o original. Outras explicativas, com o argumento de não pertencer à linha editorial, ainda que a editora recebesse 50 originais por semana. Rory manuseia essas cartas frente à câmera, perpassando o drama do autor frente à dificuldade de publicá-las a partir do método tradicional, ou seja, por meio de editoras.

$\mathrm{O}$ roteiro do filme desvela um cenário em que mesmo grandes agentes e importantes editoras rejeitam autores desconhecidos e jovens escritores, estabelecendo a lógica do mercado editorial, comum às editoras, isto é, o receio de investir em autores desconhecidos do 
público. Tal procedimento leva a crer que "ao mesmo tempo em que existem diferenças em nível mundial entre os mercados editoriais, também ocorrem semelhanças entre eles", conforme apontam Jaimeson Garcia e Marília Barcellos em estudo sobre o setor (GARCIA; BARCELLOS, 2015, p. 2). A busca de um editor que possa/queira publicar o livro faz parte do drama vivenciado no filme pelo jovem autor. Aliás, trata-se de tema recorrente na área literária, em que o bem simbólico encontra resistência no capital econômico do mercado. Pierre Bourdieu levanta essa questão, dizendo que a publicação de obras de autores desconhecidos e de autores consagrados constituem lógicas coexistentes e, ao mesmo tempo, antagônicas, em seu modo de produção e de circulação (BOURDIEU, 1996).

Dito isso, o sociólogo traz à tona a escolha do investimento a ser realizado não só na publicação, como também no autor, investimento esse relacionado ao período de retorno financeiro para o negócio do livro. No caso do filme, o capital econômico, representado pelas vendas do livro publicado com a autoria de Rory, somente se torna possível pelo valor estético da escrita do velho homem. Eis, pois, onde se encontra o capital simbólico: no valor imensurável do texto. Por outro lado, o texto do próprio Rory não teve êxito, nem mesmo como investimento a longo prazo. O jovem escritor recebeu muitos 'nãos'. Todavia, tudo isso faz sentido, ao se considerar que, não havendo uma demanda pré-existente, a lógica de comercialização relacionada ao ciclo de duração minimizará (ou não) os riscos do empreendimento:

(...) destinado a assegurar o recebimento acelerado dos lucros por uma circulação rápida de produtos reservados a uma obsolescência rápida; e, de outro lado, empreendimentos com ciclo de produção longo, baseado na aceitação do risco inerente aos investimentos culturais e sobretudo na submissão às leis específicas do comércio de arte: não tem mercado no presente, essa produção inteiramente voltada para o futuro tende a constituir estoques de produtos sempre ameaçados de recair no estado de objetos materiais. (BOURDIEU, 1996, p. 162 a 165).

Diante disso, compreende-se a postura do agente literário que, embora tenha chamado o escritor a seu escritório, ele acaba por rejeitar o original de Rory. Mais uma vez, tem-se Bourdieu a esclarecer que "as possibilidades de recuperar os gastos, quando se edita um jovem escritor, são pequenas. Um romance que não faz sucesso tem uma duração de vida (a curto prazo) que pode ser inferior a três semanas" (BOURDIEU, 1996, p. 162-165), de modo a não contemplar o capital econômico, tampouco o simbólico, que constituem as balizas do equilíbrio no campo. Ao passo que uma estética comprovada, como é o caso de obras 
premiadas, garantem a inserção da obra no acervo de comercialização por longo tempo, prolongando o retorno do investimento.

\subsection{Direito autoral e o plágio}

Em As palavras, o autor desconhecido tem sua obra copiada, palavra por palavra, e as palavras são suas, conforme lembra, para além das palavras tecladas, ao declarar "- Você roubou a minha vida". No entanto, essa reescrita foi justamente o que fez dele um autor. No final, quando Rory declara amar o livro, a cena contempla um olhar de satisfação no close-up do velho homem. Ali, portanto, emerge o reconhecimento de seu trabalho.

Longe de comparar a atitude de Rory com a intencionalidade de escrever tal um novo Cervantes, como outrora o fizera Pierre Menard, em Ficções, de Jorge Luis Borges - uma vez que a culpa de sua escolha permanece em suas costas -, ao contrário do que o velho homem o orienta, ao dizer "- não olhe para trás", o ocorrido com o texto foi o que permitiu fazer do desconhecido um autor, mesmo que anônimo, além de ensejar a circulação do texto e sua recepção junto aos leitores/consumidores. Logo, o papel de Rory é fundamental na cadeia produtiva, além de nela ocupar um lugar, não de produção ou de criação, mas a de assumir a função de difusão e circulação no campo literário e editorial.

Em As palavras, publicar e fazer chegar ao circuito do mercado um texto que não circularia de outra maneira cresce e faz sentido. Por ironia do destino, o autor da primeira escritura se encontrava vivo e atento, facultando a imbricação da constelação entre autor(es), história(s) e um novo nível de problemas que surgem para além da anterior questão, a respeito do papel do escritor e da profissionalização dessa função cultural e simbólica.

\subsection{Deu certo! Vendas e marketing}

Na cadeia de valor de Thompson, é com a publicação de Lágrimas das janelas e o devido sucesso de crítica e de vendas, que a posição do autor muda no campo. Rory passou a usufruir de capital financeiro e, por sua vez, sua posição no campo cambiou para a de um autor reconhecido. Tal como o agora consagrado escritor de Paris é uma festa que, antes, se fazia identificar com os autores pobres, agora Rory passa a ser um jovem reconhecido, sucesso de crítica, com livro na Amazon a \$19,99, 142 likes e 3.082 olhadas (aparece sem data). Assoma na tela em primeiro lugar na lista dos mais vendidos, classificado como editora IPC, a $\$ 27,00$. 
Agora, sucesso de crítica, clipagem de jornais passam em cena, evento de autógrafos, entrevistas, tudo relacionado ao campo das vendas, divulgação e marketing. A trajetória da publicação culmina com sua premiação em cerca de um terço do filme, anunciado pelo autor consagrado, Clay, como final da primeira parte do livro. O evento da Academia Americana de Artes e Letras ocorre, em Nova York, segundo placa na entrada do prédio, no Hotel Empire Terrasse, onde se encontra o velho homem, nascido em 1926, empunhando o guarda-chuva, com seu chapéu e casaco, enquanto o casal entra na limusine (temporalmente, é retomada uma das cenas iniciais do filme).

Leitores/espectadores lotaram a capacidade do auditório para escutar do autor a história narrada. Fiéis acompanham-no no intervalo do evento e a conversa assume um rumo pessoal e intimista entre a personagem-leitora Daniella e o escritor Clay, já em direção ao desfecho do filme. O investimento financeiro em marketing para o lançamento do jovem escritor é um risco para a editora. No entanto, o sucesso no investimento em Rory foi alcançado, garantido pela qualidade do conteúdo.

\subsection{Os leitores}

O filme lança para o espectador a missão de assumir o julgamento dos atos do escritor e o papel do autor, porém, mais especificamente, além de repetir, ele abre espaço para não se dizer que houve a mesma interpretação. O plágio inexiste, sim, porque o tempo, isto é, a reescrita em uma enorme passagem de tempo abre brecha para a interpretação do leitor. O que sentiu o leitor agora, e o que pensou aquele outro leitor em épocas distintas... O que sentiu o leitor e, posteriormente, o que sentirá o escritor dessa mesma obra... A verdade é que as palavras situam-se para além da escrita. As palavras encontram-se estendidas na imaginação e inscritas na vida do sujeito. E parece que é justamente isso que o autor do original diz para o novo autor: “- Não importa, esse texto já não é mais meu. Deixe-me seguir a vida”. Pode-se compreender, portanto, que o autor desconhecido abdicou daquela pessoa que ficou no passado. Já não há mais a identificação com o que escreve, todavia, há mais com o que vivenciou: a perda da filha e, posteriormente, a da esposa.

O enredo do filme sugere uma transcendência para além da ética, quer dizer, o plágio, nesse caso, existe, mas não a violação de direitos autorais, posto não haver registros legais da obra efetivados pelo velho homem. Ainda que os conceitos se aproximem, as diferenças os distinguem:

Primeiro, o plágio geralmente é uma ofensa ética, enquanto a violação de direitos autorais sempre carrega o potencial de consequências legais. 
Segundo, o plágio trata principalmente de copiar material sem a devida atribuição, enquanto a violação de direitos autorais se refere ao empréstimo de partes significativas de uma obra, sem a permissão do detentor dos direitos autorais, independentemente de o citado ser citado ou não. (Historians.org, s/d).

Ao mesmo tempo, em A aventura do livro, o historiador Roger Chartier lembra que “[...] todos os processos modernos sobre a propriedade literária, em particular, em torno da noção de imitação, de plágio, de empréstimo, já estão ligados a esta dupla questão: a dos critérios, que caracterizam a obra independentemente de suas diferentes materializações, e a de sua identidade específica" (CHARTIER, 1998, p. 67). Nesse sentido, a cópia idêntica do texto, feita por Rory, implica reprodução da obra em todo seu estilo de escrita. E mesmo que o velho homem, impedido por intempéries do destino de prosseguir na publicação do livro, ele, como história mesmo de vida, existe, e se apresenta a Rory. A partir desse movimento, é criada a autoria. Tarde demais para Rory que já fizera sua escolha: assumir o papel de autor de As palavras. Assim, mesmo que em segredo, no mais recôndito de seu íntimo, ele sabe que há uma violação de propriedade intelectual. No filme, o gosto pelas palavras está mais no seu manuseio pelos autores, e menos na intertextualidade, que é pontualmente referida ao longo do filme, como, por exemplo, na leitura do bilhete de despedida da esposa, e no trecho recitado pelo autor original, a fim de identificar a cópia do romance. Nenhuma referência, porém, à técnica: ao estilo da escrita dos três autores. O foco, aqui, manteve-se no papel de escritor, na questão da autoria, no mistério do desenlace no final da história. O que se destaca é a interpretação do leitor/espectador, costurando as pistas deixadas ao longo das imagens: ora o abraço sobreposto dos casais junto à pia da cozinha, ora a foto de uma mulher dentro do livro de Clay, encontrada por Daniella no final do filme; por vezes, detalhes no jeito de arrumar a gravata e no gosto pelo vinho encontrado, ou mesmo nos gestos do autor consagrado tanto quanto nos do jovem escritor.

A narrativa se desenvolve assim, ora na voz de Clay, ora na do velho homem, desfiando a história em memórias, num ir e vir fragmentado de elipses, a fim de manter o espectador sob suspense.

\section{CONSIDERAÇÕES}

Os temas tratados no filme confluem para as etapas do processo editorial e atendem a parte da cadeia produtiva do livro. Percebe-se a rede de relações entre agentes e organizações pertencentes ao campo editorial, seja na abordagem sobre a criação literária e a 
profissionalização dos personagens escritores, seja na condução da carreira por meio de agentes literários e de editores, na presença do autor em eventos de marketing, por exemplo, como a leitura pública em voz alta e nas vendas com autógrafos; e seja, ainda, na atuação dos formadores de opinião, crítica, jornalistas, ou mesmo na inserção dos leitores de maneira bem direta com os escritores, a ponto de criar reflexões a respeito da metalinguagem sobre a vida pessoal e intelectual. Abrindo-se um pouco mais o leque, pode-se ampliar a análise em direção à questão dos narradores e à representação do gênero no roteiro em que as personagens - escritores e premiados - têm nos bastidores das relações pessoais a presença de esposas, personagens marcantes e fortes, influenciadores no destino desses autores.

As palavras emitidas no filme ecoam por caminhos diversos do mundo editorial, ao suscitar o plágio, a propriedade intelectual, o universo editorial e seus pareceres de originais rejeitados, os contatos a partir do recurso social, a busca do recurso financeiro para o jovem escritor, o capital econômico para as editoras, considerando o que vai ou não ser publicado, além do quanto está carregado de capital de bens simbólicos e de recursos econômicos ao alcance, ou não, dos editores. O propósito, ao fim e ao cabo, não consiste em saber se houve plágio, ou não houve plágio, mas, sim, no quanto um original datilografado, engavetado, ou sem se fazer circular e alcançar seu público, prescinde de ser publicado para pertencer ao campo editorial. E isso se dá ao mesmo tempo em que o sujeito que escreve e as influências que o antecedem fazem esvair a originalidade do próprio texto. Em assim sendo, menos ética e menos direitos autorais, uma vez que ao autor desconhecido não lhe cabia ações legais; desse modo, mais questão de propriedade intelectual, e mais relação das ideias com o mundo que a cerca e o campo em que está inserido, com todas as relações de poder da cadeia de valores, utilizando os recursos capitais que lhe são disponibilizados, conforme se encontram relacionados a partir das ciências sociais.

Ao contrário do que se possa pensar, As palavras não é original proveniente de um livro, porquanto ele é o próprio livro, no formato audiovisual. Uma história de plágio, contada em duas vozes: a do escritor consagrado Clay, supostamente autor da história, e a do velho homem, o autor do original extraviado e, anos depois, encontrado, e sendo apropriado por Rory.

Coincidências na relação EUA-França, em meio a conflitos pessoais e profissionais. Diante de tantos pontos a percepcionarem os elementos do campo editorial, só se pode agradecer aos realizadores desse filme, por possibilitarem uma obra com tantas leituras, a partir da linguagem audiovisual. 


\section{REFERÊNCIAS}

ADOROCINEMA. Portal. As palavras. Disponível em: <http://www.adorocinema.com/filmes/filme190358/>. Acesso em 20/02/2020.

ARTSANDLETTERS. American Academy of Arts and Letters. Site. Disponível em: $<$ https://artsandletters.org/>. Acesso em 20/05/2020.

AS PALAVRAS| The words. Direção: Brian Klugman; Lee Sternthal. Produção: Animus films; Serena films. Distribuição: Imagem Filmes. Estados Unidos, 2012. Filme. Disponível no Youtube em: < https://www.youtube.com/watch?v=3CHTaAWCp8Y>. Acesso 14|02|2020.

ASSIS BRASIL. L. A. Escrever ficção: um manual de criação literária (org). Roberto Amábile. São Paulo: Companhia das Letras, 2019.

BARCELLOS, Marília de Araujo. O sistema literário brasileiro atual. Pequenas e médias editoras. Tese de doutorado. Departamento de Letras, Programa de Pós-Graduação em Estudos de Literatura. Pontifícia Universidade Católica do Rio de Janeiro, 2006.

BORGES, Jorge Luis. Pierre Menard, autor de Quixote. In: Fiç̧ões. Trad. Davi Arrigucci Jr. São Paulo: Companhia das Letras. 2007.

BOURDIEU, Pierre. A economia das trocas simbólicas. São Paulo: Perspectiva, 1982. Letras, 1996.

As Regras da Arte: Gênese e estrutura do campo literário. São Paulo: Companhia das

CHARTIER, Roger. A aventura do livro: do leitor ao navegador. Conversações com Jean Lebrun. São Paulo: Imprensa Oficial do Estado de São Paulo/Editora UNESP, 1998.

GARCIA, Jaimeson Machado. Monografia (Des)ordem na cadeia produtiva do livro: um estudo de caso sobre o livro Ryotiras Omnibus. Trabalho de Conclusão de Curso. Orientação Marília de Araujo Barcellos. Departamento de Ciências da Comunicação da Universidade Federal de Santa Maria, Curso de Comunicação Social - Produção Editorial, 2014.

; BARCELLOS, Marília de Araujo. Desdobramentos do Papel dos Agentes Formadores da Cadeia Produtiva em Publicações: um caso de Crowdfunding. v. 4, n. 2 (2015): Revista Brasileira de História da Mídia - Dossiê Temático: História do Livro e da Leitura (v.4, n.2, 2015). Disponível em: <https://revistas.ufpi.br/index.php/rbhm/article/view/4169/2478>. Acesso em 20/02/2020.

HEMINGWAY, Ernest. Paris é uma festa. Rio de Janeiro: Civilização Brasileira, 1969.

HISTORIANS.ORG. Historians American Historical Association. Definindo plágio. Disponível em: $<$ https://www.historians.org/teaching-and-learning/teaching-resources-for-historians/plagiarismcurricular-materials-for-history-instructors/defining-plagiarism> . Acesso em 20/05/2020.

THOMPSON, John B. Mercadores de cultura: o mercado editorial no século XXI. São Paulo: Editora Unesp, 2013.

WIKILIVROS. Movimento Wikimedia. Rue Cardinal-Lemoine. Disponível em <https://pt.wikibooks.org/wiki/Ficheiro:Rue_Cardinal_Lemoine-Plaque_Hemingway.JPG>. Acesso em 20/03/2020. 
Marília de Araujo Barcellos é Professora Associada do Departamento de Ciências da Comunicação da Universidade Federal de Santa Maria; foi coordenadora do Curso de Comunicação Social - Produção Editorial (UFSM); É doutora em Letras | Estudos de Literatura (PUC-Rio), e tem estágio doutoral em Paris (EHESS). Atuou no mercado editorial, quando aprendeu a apreciar livros em qualquer formato, desde que bem elaborados.

\section{@ (요 $\mathbb{Q}$}

Esta obra está licenciada com uma Licença

Creative Commons Atribuição-NãoComercial-CompartilhaIgual 4.0 Internacional 